\section{ScienceDirect}

Engineering Failure Analysis xxx (2008) xxx-xxx

\section{ENGINEERING \\ FAILURE \\ ANALYSIS}

www.elsevier.com/locate/engfailanal

\title{
Mould steels repaired by laser welding
}

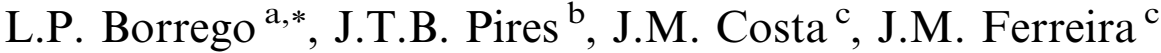 \\ ${ }^{a}$ Department of Mechanical Engineering, Instituto Superior de Engenharia de Coimbra, IPC, Rua Pedro Nunes, 3030-199 Coimbra, Portugal \\ ${ }^{\mathrm{b}}$ Department of Industrial Engineering, Escola Superior de Tecnologia, IPCB Avenida do Empresário, 6000-767 Castelo Branco, Portugal \\ ${ }^{\mathrm{c}}$ Department of Mechanical Engineering, University of Coimbra, Polo II, Pinhal de Marrocos, 3030-201 Coimbra, Portugal
}

\begin{abstract}
Laser-deposit welding, by using Nd-YAG, is a mould repairing process, which has the advantages relatively to the traditional methods of achieving a less change of the metal composition around the repaired zone and permitting a very accurate deposition of a small volume of the filler material in the area chosen at the work-piece surface. This paper presents a fatigue study in specimens of two base materials used in mould production (AISI H13 and P20). Filler material as well as welding parameters were analysed in order to obtain better fatigue strength. The tests were carried out under constant amplitude loading, with two stress ratios $R=0$ and $R=0.4$. Welded specimens were prepared with $\mathrm{V}$ notches and filled with laser welding deposits. The fatigue results are presented in the form of $S-N$ curves obtained in welded and non-welded conditions. Complementary measurements of hardness profiles and SEM analysis were carried out to understanding the fatigue behaviour and failure sites. The laser-deposit material was the weaker region in both steels, due to a high level of tensile residual stresses and also to some planar defects that are potential failure sites. Fatigue crack initiation is therefore reduced and the fatigue propagation life is enhanced. A significant mean stress effect in the base material was also observed in both mould steels.
\end{abstract}

(C) 2008 Elsevier Ltd. All rights reserved.

Keywords: Mould producing; Laser repairing; Welded joints; Fatigue

\section{Introduction}

Mould producing is one of the more relevant Portuguese industries using high CAD/CAM technologies. The shape and manufacturing of tools for moulds are usually extremely exact and consequently very expensive. Therefore, during moulds manufacturing, the correction of localized imperfections due to design or execution as well as tool marks is very frequent.

In injection and bow moulds for plastic products and in die casting processes of aluminium and magnesium alloys, these tools are subjected to strong thermo-mechanical loads which can lead to damage of the moulds surface in the form of wear or fatigue cracks.

\footnotetext{
* Corresponding author. Tel.: +351 962560101; fax: +351 239790331.

E-mail address: borrego@isec.pt (L.P. Borrego).
} 
Laser-deposit welding, by using modern ND-YAG lasers, is a new repair process, very flexible, that has the advantage relatively to the traditional methods (Micro-plasma and TIG methods) of achieving less change of the metal composition around the repaired zone. Moreover, it permits a very accurate deposition of a small volume of filler material at the area chosen in the work-piece surface, without distortion, even in the case of a small thickness of $0.2 \mathrm{~mm}$.

Taking into account the costs involved to produce a new mould, is obvious the relevance of the possibility in repairing moulds without significant loss of quality. Therefore, if the operation life of dies could be successfully extended by a regular maintenance of die parts, the final price of moulds would be significantly improved.

An important property for repairing mould steels is a good weldability in both states prior and after the post-weld heat treatment. Gehricke [1] reported the superiority of the maraging steels relatively to hot-working tool steels. Grum and Slabe also observed $[2,3]$ that the heat treatment of maraging steels, including solution annealing and precipitation annealing, is less difficult than the heat treatment of hot-working tool steels. Despite these advantages of the maraging steels, the majority of the moulds produced in Portugal for die casting processes of aluminium and magnesium alloys as well as for injection and bow moulds for plastic products use hot-working tool steels (AISI H13 and AISI P20).

The influence of the micro laser repairing welding on the fatigue strength of welded parts is a recent subject and therefore insufficiently analysed. There are only few research studies in materials welded by Nd-YAG laser such as, Waspaloy [4], NiTi alloy [5], titanium alloy [6] and automotive aluminium alloys [7], but none of these analyses the fatigue behaviour.

For moulds steels there are also no research studies about the laser-deposit welding process effects in respect to microstructure, hardness and residual stresses variations in the laser-deposited layer and in the heat-affected zone. These variations will have an important influence in the thermal-mechanical fatigue strength of the moulds parts.

In recent work [8], the authors obtained the fatigue strength of H13 and P20 mould steels, for both nonwelding and surface laser welded specimens with U notches. Filler material and welding parameters used in the preparation of the welded specimens were the ones currently used in the mould industry. The obtained data indicated that the repaired joints using Nd-YAG laser welds present significantly lower fatigue strength than base materials, mainly due the high number of defects in the welds, which promote crack initiation, and, therefore are potential failure sites. The high tensile stresses obtained in the laser-deposited material also contributed to that trend. Therefore, the optimization of the welding process is important to obtain better mechanical properties of repaired moulds.

In the present study, an Nd-YAG micro laser process will be used in order to simulate the repair of damaged tool surfaces. A fatigue analysis of the H13 and P20 mould steels with surface defects repaired by the laser process will be performed with several filler materials, welding parameters and welding geometry. The fatigue data obtained with the new welding conditions will be compared with the previously obtained $S-N$ curves in welded and plain specimens [8]. Finally, microhardness analysis and evaluation of the residual stress state of the laser welded regions as well as SEM observations will also be performed after laser repair.

\section{Experimental details}

This research was conduced using two base materials, namely hot-working tool steels: AISI H13 and AISI P20. The P20 steel was investigated in the as received condition, i.e., with quenching and tempering treatment, while the H13 steel was submitted to quenching and tempering only after machining. The chemical composition and the mechanical properties of these alloys are depicted in Tables 1 and 2, respectively.

Table 1

Chemical composition of the analysed mould steels $(\mathrm{wt} \%)$

\begin{tabular}{|c|c|c|c|c|c|c|c|c|}
\hline \multicolumn{2}{|c|}{ Mould steel } & \multirow[t]{2}{*}{$\mathrm{C}$} & \multirow[t]{2}{*}{$\mathrm{Si}$} & \multirow[t]{2}{*}{$\mathrm{Mn}$} & \multirow[t]{2}{*}{$\mathrm{Cr}$} & \multirow[t]{2}{*}{ Mo } & \multirow[t]{2}{*}{$\mathrm{Ni}$} & \multirow[t]{2}{*}{$\mathrm{V}$} \\
\hline AISI & DIN & & & & & & & \\
\hline H13 & X.40.CrMoV.5.1 & 0.39 & 1.0 & 0.4 & 5.2 & 1.3 & - & 1.0 \\
\hline $\mathrm{P} 20$ & 40.CrMnNiMo.8.6.4 & 0.37 & 0.3 & 1.4 & 2.0 & 0.2 & 1.0 & - \\
\hline
\end{tabular}

Please cite this article in press as: Borrego LP et al., Mould steels repaired by laser welding, Eng Fail Anal (2008), doi:10.1016/j.engfailanal.2008.02.010 
Table 2

Mechanical properties of the mould steels

\begin{tabular}{|c|c|c|c|c|c|}
\hline \multicolumn{2}{|c|}{ Mould steel } & \multirow[t]{2}{*}{$\sigma_{\mathrm{UTS}}(\mathrm{MPa})$} & \multirow[t]{2}{*}{$\sigma_{\mathrm{YS}}(\mathrm{MPa})$} & \multirow[t]{2}{*}{$\varepsilon_{\mathrm{r}}(\%)$} & \multirow[t]{2}{*}{$\mathrm{HV}$} \\
\hline AISI & DIN & & & & \\
\hline H13 & X.40.CrMoV.5.1 & 1990 & 1650 & 9 & 550 \\
\hline $\mathrm{P} 20$ & 40.CrMnNiMo.8.6.4 & 995 & 830 & 12 & 300 \\
\hline
\end{tabular}

The H13 steel is mainly used in the production of moulds for die casting processes of aluminium and magnesium alloys and the P20 steel in the production of moulds for injection and bow of plastic products.

Fatigue tests were performed with rectangular cross-section specimens. Welded specimens were prepared with $\mathrm{V}$ notches and filled with laser welding deposits in order to simulate the repair of damaged tool surfaces. Fig. 1 illustrates the major dimensions of the samples used in the tests. The radius of the $\mathrm{V}$ notch tip was $0.5 \mathrm{~mm}$. Several laser-deposited layers were performed in these specimens using filler wire.

Welding was conduced with an Nd-YAG laser system, HTS 180 Laser Tool, using a pulsating electric current with $6 \mathrm{~Hz}$ and $8 \mathrm{~ms}$ of impulse time. A filler wire with $0.4 \mathrm{~mm}$ diameter was used. An Ar/He-mixture $(5 \%$ $\mathrm{He}$ ) with a flow of $0.6 \mathrm{l} / \mathrm{min}$ was used as shielding gas. The filler material used for the $\mathrm{H} 13$ steel specimens was a stainless steel while for the P20 steel specimens several alloy steels were analysed. The chemical composition of the filler wires are presented in Table 3.

Four combinations of welding parameters were analysed in order to obtain the lower level of defects. As indicated in Table 4 the power was ranged between $58 \%$ and $63 \%$ of maximum laser system power $(180 \mathrm{~W})$ and the laser beam diameter was ranged between 0.5 and $0.6 \mathrm{~mm}$. The best combination was selected after optical microscopy analysis of the level of defects observed in the welds cross-sections.

All the fatigue tests were performed in load control using a computer-controlled servo-hydraulic Instron machine with $100 \mathrm{kN}$ capacity. The tests were carried out under constant amplitude loading, with two stress ratio $R=0$ and $R=0.4$. All tests were conducted in air, at room temperature and with a load frequency of $25 \mathrm{~Hz}$. The specimens were clamped by hydraulic grips.

In order to characterise the welded joint and the heated affected zone (HAZ) Vickers hardness profiles were obtained using a Struers Type Duramin-1 microhardness tester, with an indentation load of $2000 \mathrm{gf}$ during $15 \mathrm{~s}$, according to the ASTM E 348 standard [9]. The hardness profiles were obtained at the repairing joint

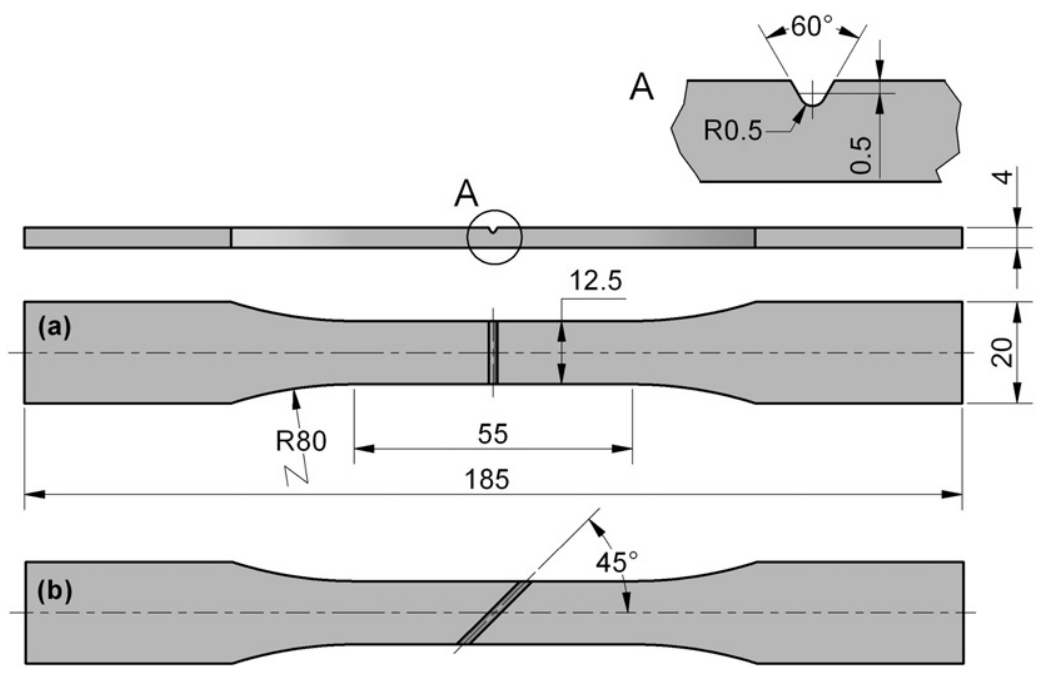

Fig. 1. Geometry of the rectangular cross-section specimens used in the tests (dimensions in mm): (a) weld angle $=0^{\circ}$; (b) weld angle $=45^{\circ}$. 
Table 3

Chemical composition of the filler wire materials ( $\mathrm{wt} \%$ )

\begin{tabular}{llllllllll}
\hline Mould steel & Wire & $\mathrm{C}$ & $\mathrm{Si}$ & $\mathrm{Mn}$ & $\mathrm{Cr}$ & $\mathrm{Mo}$ & $\mathrm{Ni}$ & $\mathrm{V}$ & $\mathrm{Fe}$ \\
\hline H13 & - & 0.15 & 1.5 & 2 & 20 & - & 7 & - & Rest. \\
P20 & A & 0.35 & 0.3 & 1.2 & 7 & 2 & - & - & Rest. \\
& B & 0.1 & 0.6 & 1.3 & - & 0.5 & - & - \\
& C & 0.25 & - & 1.4 & 1.6 & 0.3 & - & 0.4 & Rest. \\
\hline
\end{tabular}

Table 4

Welding parameters analysed

\begin{tabular}{lll}
\hline Type & Laser power $(\mathrm{W})$ & Laser beam $\varnothing(\mathrm{mm})$ \\
\hline (a) & 104.4 & 0.5 \\
(b) & 106.2 & 0.5 \\
(c) & 111.6 & 0.6 \\
(d) & 113.4 & 0.6 \\
\hline
\end{tabular}

cross-sections, along a longitudinal line at $0.5 \mathrm{~mm}$ from the specimen surface. The measurements were performed at each $0.15 \mathrm{~mm}$, along a distance from the laser weld centre until hardness stabilization.

After laser repair the residual stress state was evaluated by the incremental hole-drilling method (IHD). For the IHD technique, high speed drilling equipment (milling guide RS-200 with air turbine, Measurements Group, Inc.) was used to perform a cylindrical blind hole. This technique is recommended since only minor drilling-induced plastic deformations occur and a satisfying hole shape can be achieved [10]. Surface strain relief was measured by a three-element strain gage rosette (ASTM type A rosette) where the gages are radially oriented around the hole at different angular positions as illustrated in Fig. 2. Using in-depth increments of $0.02-0.08 \mathrm{~mm}$, strain relief was measured after each depth increment to about $1 \mathrm{~mm}$ below the surface. Smaller steps were carried out close to the surface to access stress gradients more precisely. The typical hole diameter was about $1 \mathrm{~mm}$. For residual stress evaluation the integral method was selected [11], using the Residual Stress Group Software [12]. The elastic constants considered were: $E=210 \mathrm{GPa}$ and $v=0.3$.

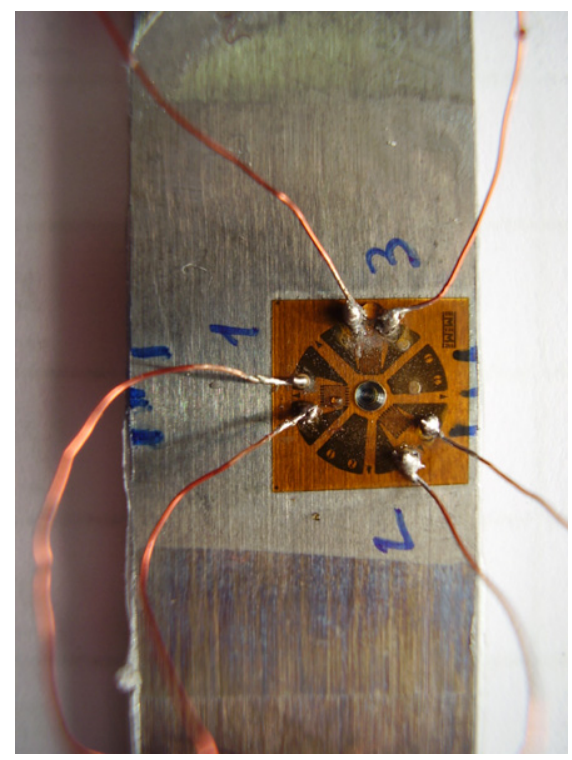

Fig. 2. Three-element strain gage rosette with gages radially oriented around the hole at different angular positions. 
Finally, SEM observations of the fatigue fracture surfaces were performed in laser welded specimens using a Philips XL30 scanning electron microscope.

\section{Results and discussion}

\subsection{Optimization of the welding process}

Fatigue strength of welded specimens of P20 mould steel is plotted in Fig. 3 as nominal stress amplitude, $\Delta \sigma / 2$, against the number of cycles to failure, $N_{\mathrm{f}}(S-N$ Wholler curves). Three series of specimens were tested with the notches filled with the three materials (A, B and C) indicated in Table 3. It can be observed that filler materials $\mathrm{B}$ and $\mathrm{C}$ present the higher fatigue strength, being material $\mathrm{C}$ the more resistant.

The mean hardness values measured near the middle of the weld deposit were: $744 \mathrm{HV}$ for material A, $406 \mathrm{HV}$ for material B and $398 \mathrm{HV}$ for material C. Material A, which presents the higher hardness is also the one that has the lower fatigue resistance. The chemical composition with a higher level of $\mathrm{Cr}$ content justifies the formations of hard microstructures. Materials $\mathrm{B}$ and $\mathrm{C}$ having lower and similar hardness present very close $S-N$ curves.

Fig. 4 shows SEM images of the fatigue surfaces obtained in P20 welded specimens filled with the materials A, B and C indicated in Table 3. Fig. $4 \mathrm{a}$ is for the type A filler material showing a rough surface where the brittle crack propagation is the main mechanism. Some secondary cracks normal to the surface can also be observed.

Fig. $4 \mathrm{~b}$ and $\mathrm{c}$ are for type $\mathrm{B}$ and $\mathrm{C}$ filler materials, respectively. Smooth fatigue surface with several planar defects normal to the surface can be observed. In both figures multiple crack initiation sites starting from the surface of these defects are visible. However, the SEM image (b) obtained for type B filler wire present a higher level of defects than image (c) obtained for type $\mathrm{C}$ material, which can explain its slightly higher fatigue resistance observed in Fig. 3.

The hardness profiles obtained at the repaired joint cross-sections of specimens welded with type $\mathrm{C}$ filler wire and using the welding processes (a)-(d), as indicated in Table 4, are shown in Fig. 5, along a longitudinal line at $0.5 \mathrm{~mm}$ from the specimen surface. The measurements were performed at each $0.15 \mathrm{~mm}$, along a distance from the laser weld centre until hardness stabilization. Four combinations of welding parameters were analysed in order to obtain the lower level of defects. It can be seen that the increase of the laser power lead to

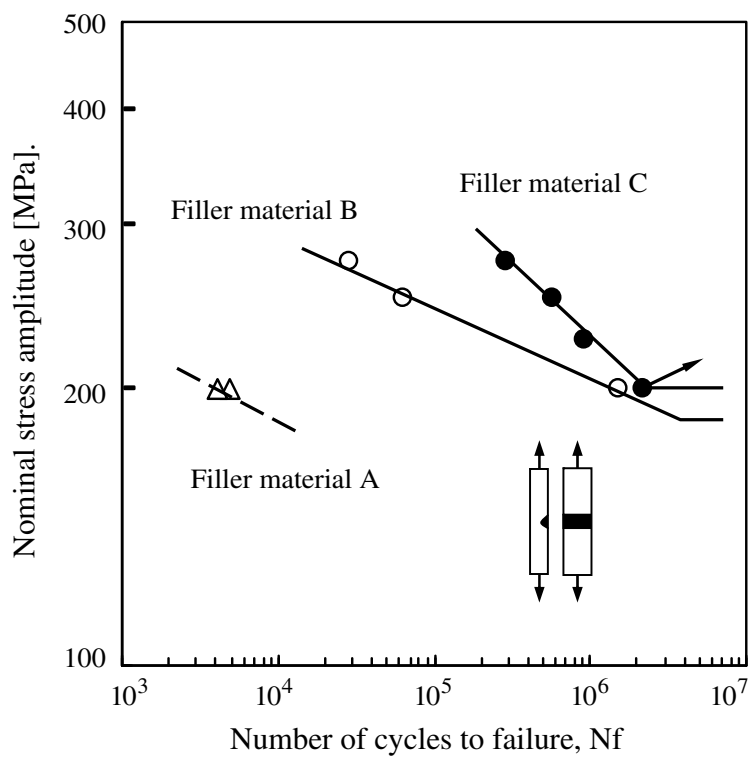

Fig. 3. $S-N$ curves for the three filler materials of Table 3. P20 mould steel, $R=0$. 

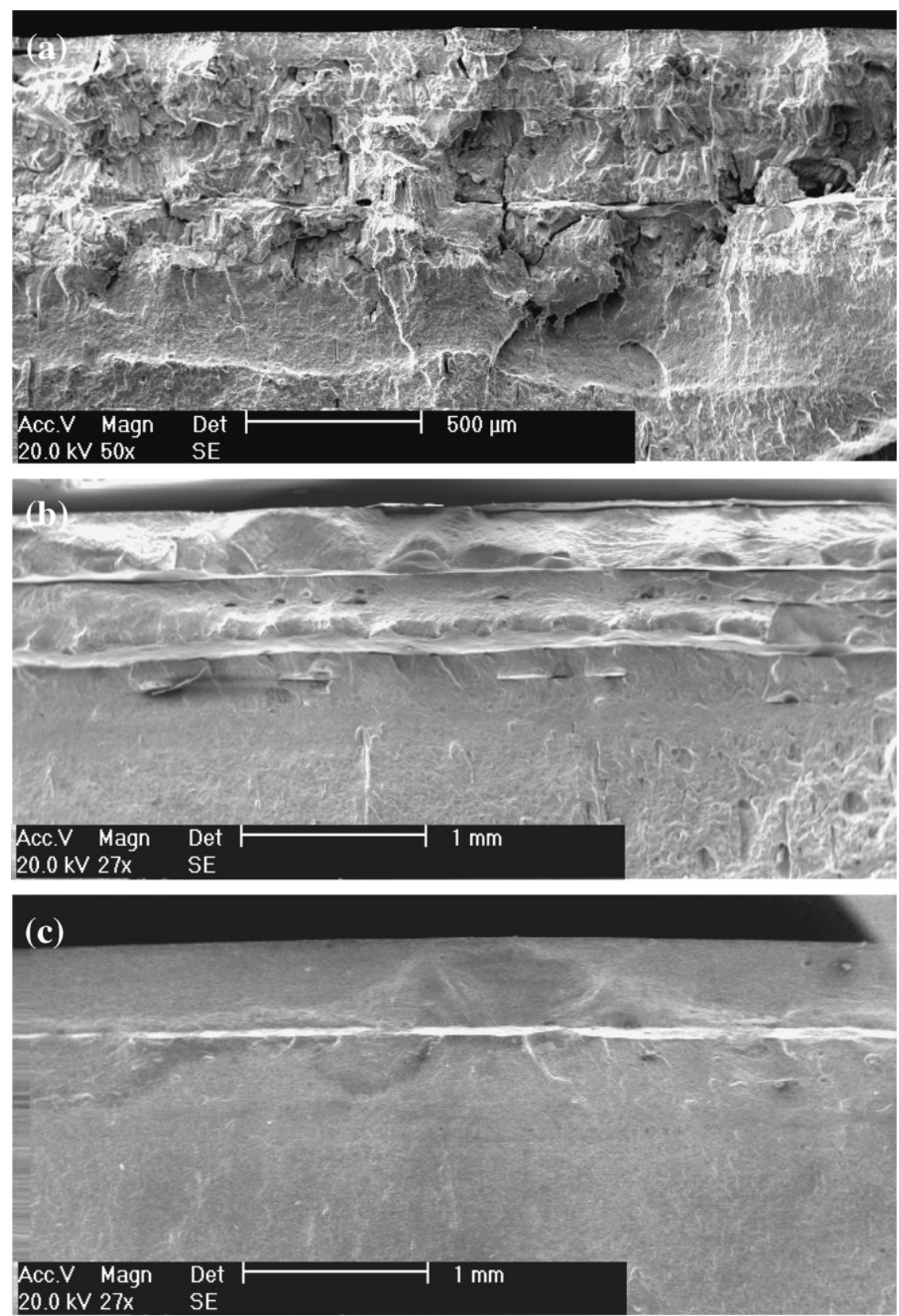

Fig. 4. Fatigue fracture appearance of the P20 welded specimens filled with filler wires: (a) type A; (b) type B; (c) type C. $R=0$, $\Delta \sigma=500 \mathrm{MPa}$.

an increase of the hardness values, specially, in the heat-affected zone. The best combination was selected after an optical microscopy analysis of the level of defects observed in the weld cross-sections.

Fig. 6 present photos obtained by optical microscopy analysis of the level of defects observed in hatched cross-sections trough the welds. Between the four combinations of welding parameters analysed in order to obtain the lower level of defects the one that provides the best results was welding processes (d). Fig. $6 \mathrm{~d}$ shows that with these parameters planar defects are virtually absent.

Following the described analysis, the filler wire type $\mathrm{C}$ was selected for repairing the P20 steel specimens and a laser power of $113.4 \mathrm{~W}$ (about $63 \%$ of the maximum power of the laser welding machine $-180 \mathrm{~W}$ ) and a laser beam diameter of $0.6 \mathrm{~mm}$ were selected as welding parameters for both P20 and H13 mould steels. 


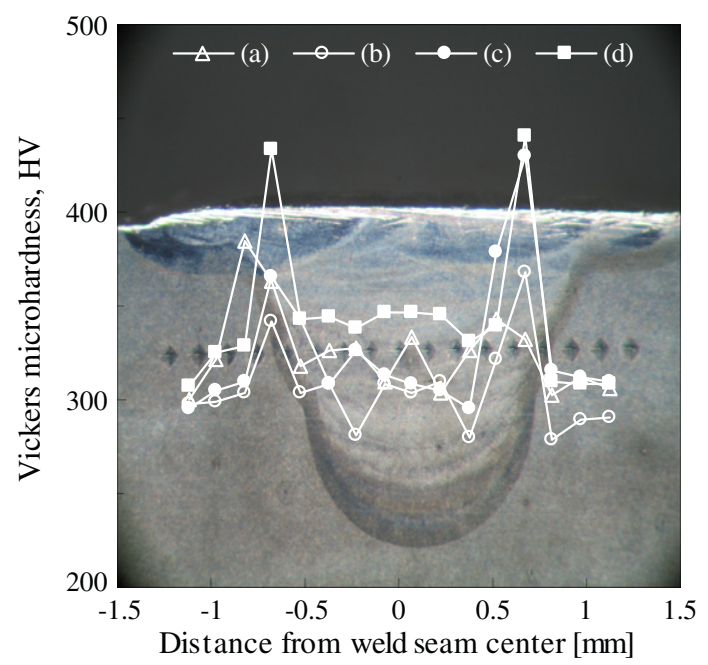

Fig. 5. Hardness profiles in laser welds: (a) $P=104.4 \mathrm{~W}, d=0.5 \mathrm{~mm}$; (b) $P=106.6 \mathrm{~W}, d=0.5 \mathrm{~mm}$; (c) $P=111.6 \mathrm{~W}, d=0.6 \mathrm{~mm}$; (d) $P=113.4 \mathrm{~W}, d=0.6 \mathrm{~mm}$. $P=$ laser power, $d=$ laser beam diameter.
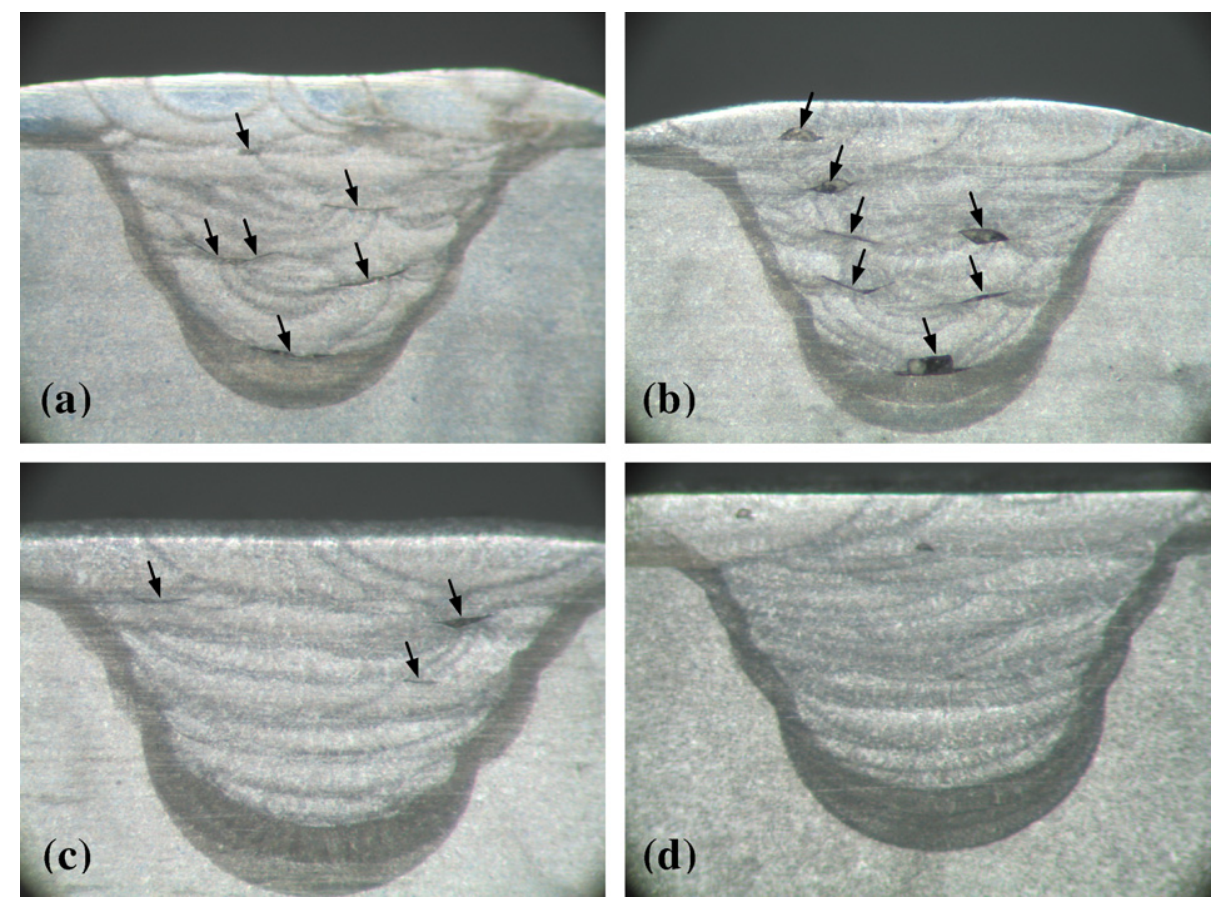

Fig. 6. Welds hatched cross section: (a) $P=104.4 \mathrm{~W}, d=0.5 \mathrm{~mm}$; (b) $P=106.6 \mathrm{~W}, d=0.5 \mathrm{~mm}$; (c) $P=111.6 \mathrm{~W}, d=0.6 \mathrm{~mm}$; (d) $P=113.4 \mathrm{~W}, d=0.6 \mathrm{~mm}$. $P=$ laser power, $d=$ laser beam diameter.

\subsection{Fatigue results}

Fatigue strength of welded and non-welded specimens are plotted in Fig. 7 for P20 mould steel as nominal stress amplitude, $\Delta \sigma / 2$, against the number of cycles to failure, $N_{\mathrm{f}}(S-N$ Wholler curves).

The results were obtained from tests performed at stress ratios $R=0$ and $R=0.4$. This figure shows an important decrease of the fatigue strength obtained at $R=0.4$ in comparison to the stress ratio $R=0$, i.e., there is a high mean stress effect in the fatigue strength of P20 steel using non-welded specimens. 


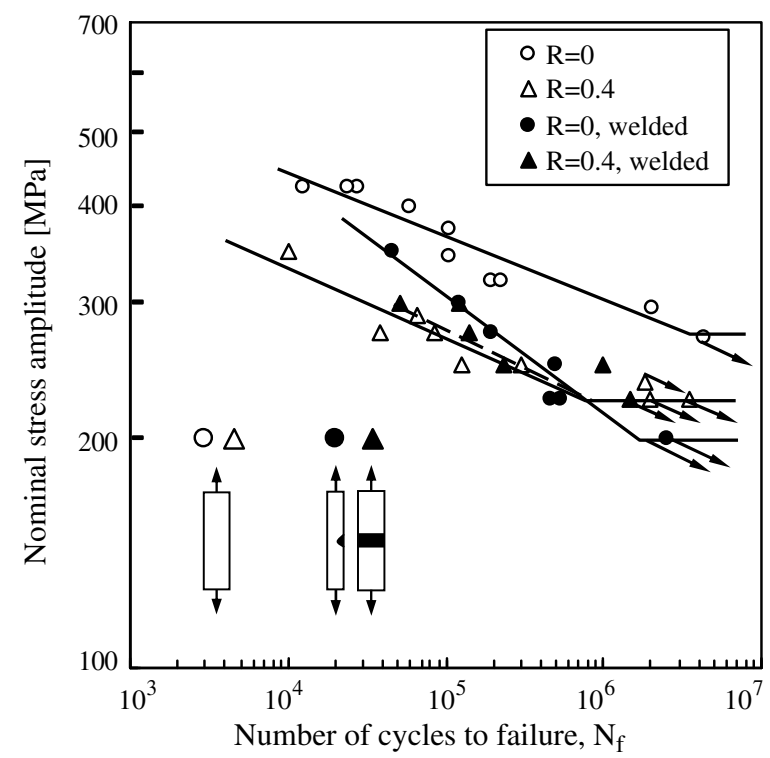

Fig. 7. $S-N$ curves for welded and non-welded P20 steel specimens. Weld angle $=0^{\circ}$.

Repaired specimens, tested at $R=0$, present a significantly lower fatigue resistance than the correspondent non-welded specimens tested at the same stress ratio. The repaired specimens have a plane surface laser welding, therefore there is no stress concentration in the weld joint. Also, the finishing of both welded and nonwelded specimens is similar. Therefore, the decrease of the fatigue strength observed in the repaired specimens must be explained in terms of other factors such as filler material mechanical properties, residual stresses or welding defects. However, the repaired specimens, tested at $R=0.4$, present a similar fatigue resistance to the correspondent non-welded specimens tested for the same stress ratio and simultaneously very close to the curve obtained for welded specimens at $R=0$. Therefore, it must be concluded that the residual stresses are probably the main factor affecting the fatigue behaviour and that the low level of planar defects obtained with the new welding parameters has only a small influence in the fatigue strength of the repaired specimens.

The residual stress state obtained after laser repairing of a P20 steel specimen, evaluated by the incremental hole-drilling method, is presented in Fig. 8. Indeed, this figure shows that the repaired specimens present very high levels of tensile residual stress at the laser-deposited material. The magnitude of these stresses increase with depth until achieving a maximum value of about $760 \mathrm{MPa}$ at approximately $0.2 \mathrm{~mm}$ from the specimen surface and of $817 \mathrm{MPa}$ at $0.33 \mathrm{~mm}$, for $y$ and $x$ directions, respectively.

The high tensile residual stresses values observed at the laser-deposited material, mainly in the direction normal to the weld, increases significantly the effective mean stress of the fatigue cycle which has a detrimental effect in fatigue lives, contributing in this way to the lower fatigue resistance observed in the repaired specimens.

The fatigue results obtained for H13 mould steel at stress ratios $R=0$ and $R=0.4$ for both non-welded and repaired specimen with $0^{\circ}$ weld angle are depicted in Fig. 9. Similarly to the observed behaviour for P20 steel the results obtained in the H13 hot-working steel show a significant fatigue strength decrease of welded specimens when compared with non-welded specimens for $R=0$. Additionally, there is also a high mean stress effect in the fatigue strength obtained with the non-repaired specimens. Furthermore, the welded specimens, tested at $R=0.4$, present also similar fatigue resistance to the correspondent non-welded specimens tested for the same stress ratio. This behaviour is also probably due to an important level of tensile residual stresses in the weld deposit of the H13 steel specimens, similar to the observed for the P20 repaired specimens, which increases the effective mean stress.

Fig. 10 compares the $S-N$ fatigue curves for non-welded specimens and welded specimens in P20 steel at $R=0$. Two series of tests performed with repaired specimens are show: one for the new welding parameters optimized as indicated above and using two directions for the welds $\left(0^{\circ}\right.$ and $\left.45^{\circ}\right)$; the other was previously 


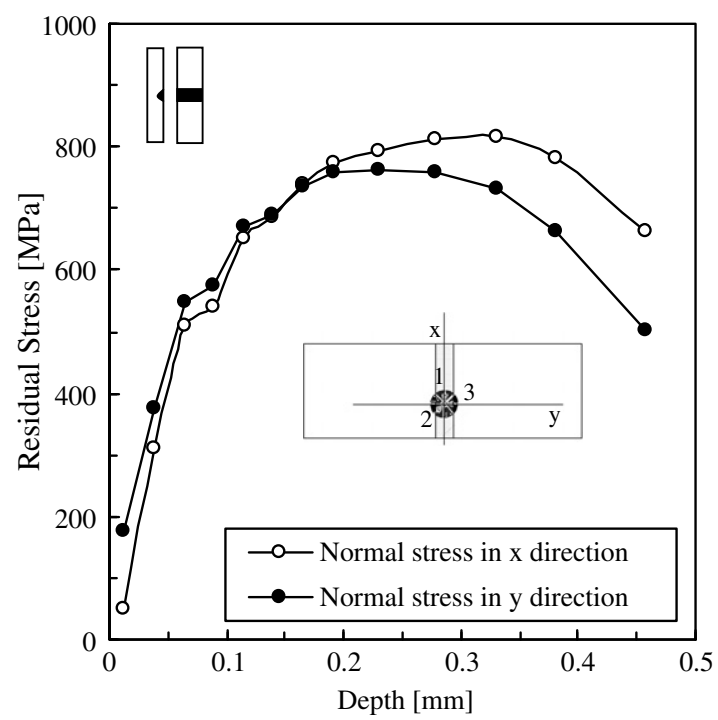

Fig. 8. Residual stress state after laser repairing. P20 steel specimen with weld angle $=0^{\circ}$.

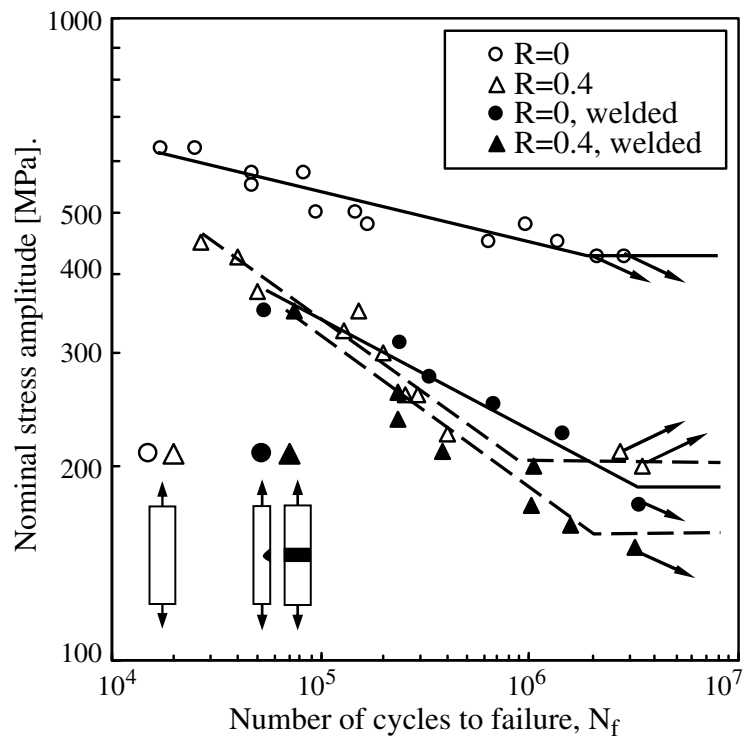

Fig. 9. $S-N$ curves for welded and non-welded H13 steel specimens. Weld angle $=0^{\circ}$.

obtained [8] using the currently welding parameters used in the mould industry. It can be clearly observed an important increase of the fatigue resistance with the optimized welding procedure previously described. Additionally, the weld angle shows no effect on the fatigue life of P20 steel repaired specimens.

The influence of the weld direction on the fatigue strength of H13 repaired specimens is depicted in Fig. 11. Similarly to the observed behaviour for the P20 steel, the weld angle shows no significant effect on the fatigue lives of $\mathrm{H} 13$ steel welded specimens for both stress ratios analysed.

Fig. 12a shows several planar defects that result from a lack of fusion between the successive laser-deposit layers. It seems that there are multiple crack initiation sites starting from the surface of these defects. These defects provide new surfaces were the crack can be more easily initiated due to the lower constraint of the plastic deformation that characterizes the surface grains of a material. However, taking in account that the defects 


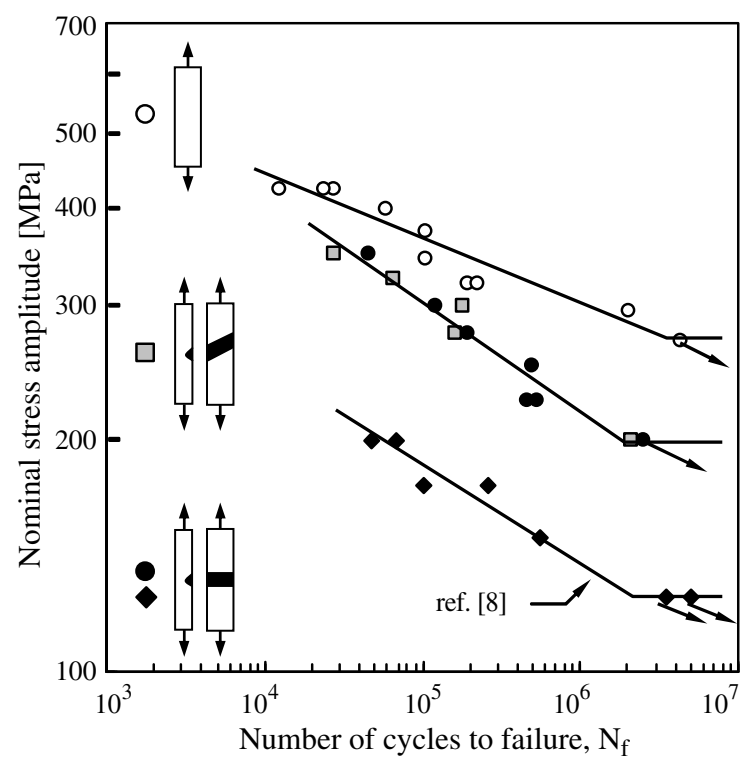

Fig. 10. Influence of welding procedure and geometry. P20 steel, $R=0$.

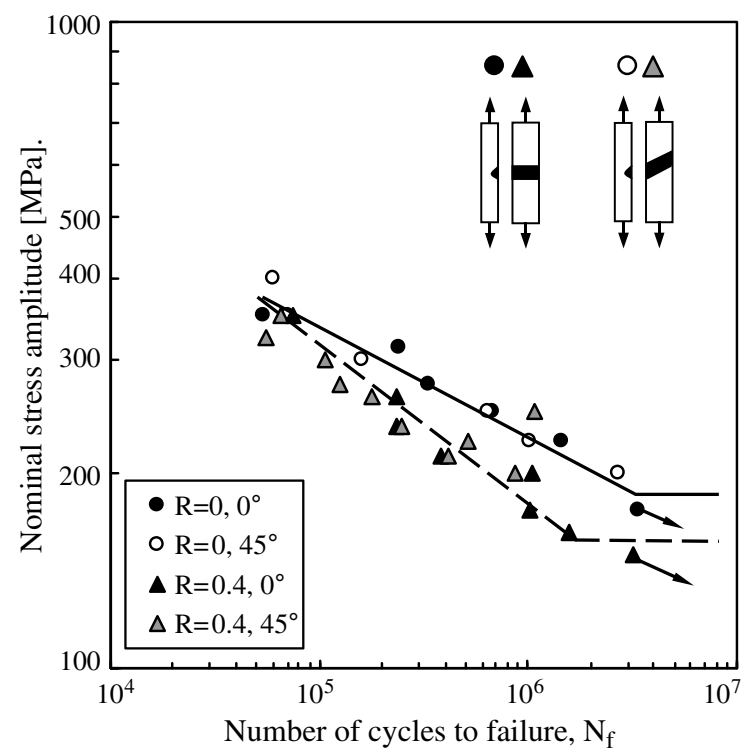

Fig. 11. Influence of welding geometry. H13 steel.

are planar and almost parallel with to the loading direction there is no detrimental effect in the fatigue resistance. In spite of the optimization of the welding process which leads to an effective increase on the fatigue resistant as observed in Fig. 10, some defects remain in the welds, although in a number significant less than the obtained with the generally welding process currently used in mould industry.

Fig. 12b is a SEM image obtained in a P20 welded specimen with a weld angle of $45^{\circ}$. In this case a single crack initiation site, starting from the specimen surface is observed. Only one important planar defect can be seen inside the weld deposit. In spite of its high dimension, the provable higher level of the residual stress near the surface and the less constrain of the surface grains can explain the initiation site observed. The direction of the weld is the obvious reason for Fig. 12b presenting a lower level of defects in comparison to Fig. 12a. 

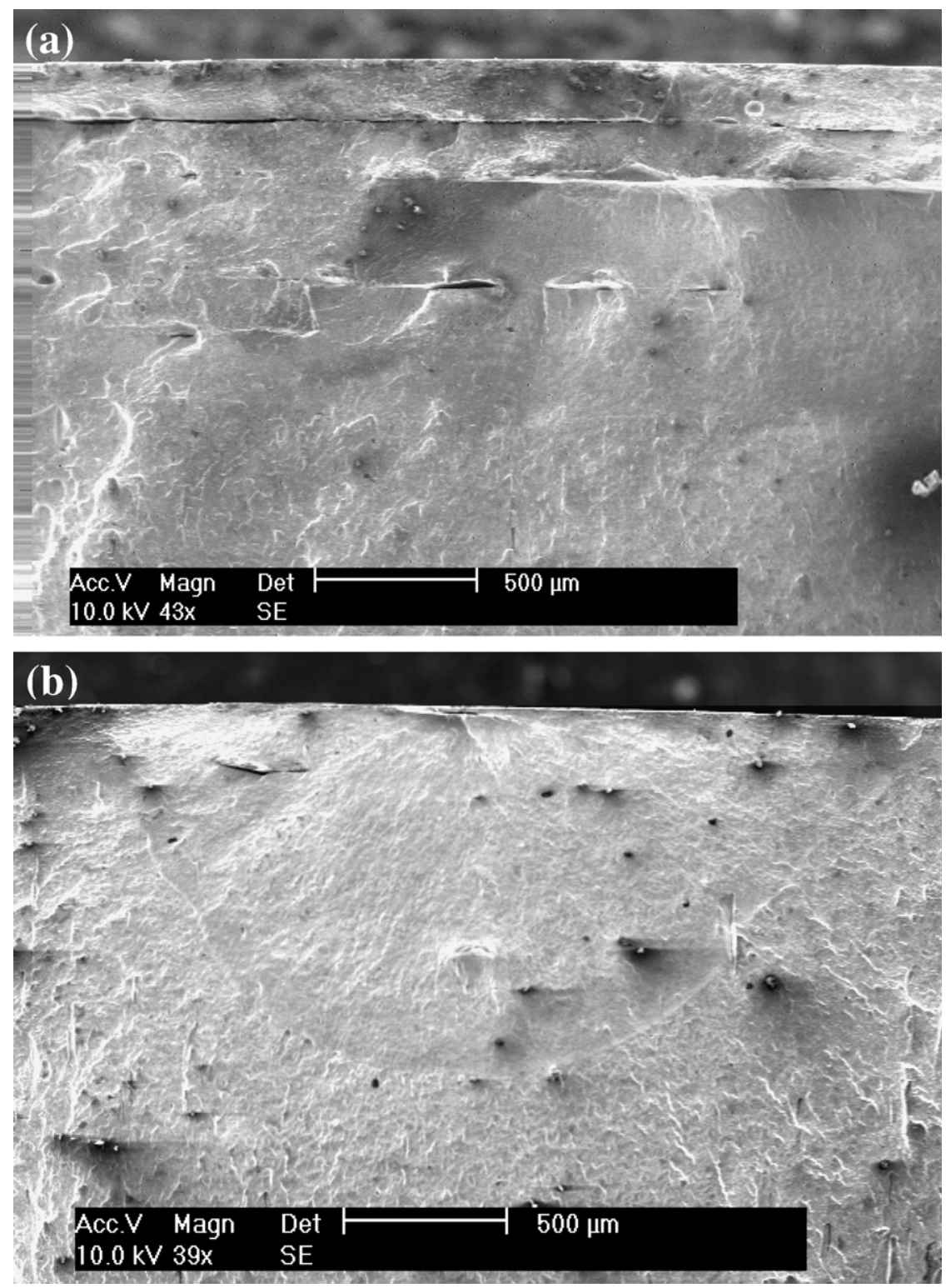

Fig. 12. Fatigue fracture appearance of the P20 mould steel repaired specimens with type $\mathrm{C}$ filler material (Table 3). $R=0$, $\Delta \sigma=550 \mathrm{MPa}$. Weld angles: (a) $0^{\circ}$; (b) $45^{\circ}$.

\section{Conclusions}

The fatigue strength of P20 and H13 mould steels was obtained in terms of $S-N$ curves, for surface laser repaired specimens. The analysis was performed with several filler materials, welding parameters and welding geometry in order to select the welding procedure that conduce to the higher fatigue resistance. In spite of the defect level improvement obtained with the new welding process, the repaired joints using Nd-YAG laser welds present significantly lower fatigue resistance at stress ratio $R=0$ than base materials, probably as consequence of the important level of tensile residual stresses observed at the weld deposit, which increases the effective mean stress and thus has a detrimental effect in fatigue life. For stress ratio $R=0.4$ no significantly effect of the weld deposits was observed in both mould steels, being the repaired specimens curves for $R=0$ and $R=0.4$ very similar and almost superimposed with the $S-N$ curve obtained for non-welded specimens at 
$R=0.4$, which is also consistent with the very high tensile residual stress level at the welds. Finally, the welding geometry shows no effect on the fatigue strength of both steels.

\section{Acknowledgments}

The authors would like to acknowledge POCI programme, project POCI/EME/55918/2004, for funding the work reported, Anibal H. Abrantes S.A. company for performing the laser welds and ThyssenKrupp Portugal company for performing the heat treatment of the specimens.

\section{References}

[1] Gehricke B. Development, properties and characteristics of a new maraging steel for die casting dies. In: Proceeding of the conference on the die casting technology in harmony with the environment, Cleveland, USA; 1993. p. 209-17.

[2] Grum J, Slabe JM. Possibility of introducing laser surfacing into maintenance service of die casting dies. Surf Coat Technol 2004;180181:596-602.

[3] Grum J, Slabe JM. A comparison of toll-repair methods using $\mathrm{CO}_{2}$ laser surfacing and arc surfacing. Appl Surf Sci 2003;208209:424-31.

[4] Li Z, Gobbi SL, Loreau JH. Laser welding of Waspaloy sheets for aero-engines. J Mater Process Technol 1997;65:183-90.

[5] Falvo A, Furgiuele FM, Maletta C. Laser welding of a NITI alloy: mechanical and shape memory behaviour. Mater Sci Eng A 2005;412:235-40.

[6] Turner MW, Crouse PL, Li L. Comparison of mechanisms and effects of Nd-YAG and $\mathrm{CO}_{2}$ laser cleaning of titanium alloys. Appl Surf Sci 2006;252:4792-7.

[7] Kuo TY, Lin HC. Effects of pulse level of Nd-YAG laser on tensile properties and formability of laser weldments in automotive aluminium alloys. Mater Sci Eng A 2006;416:281-9.

[8] Borrego LP, Pires JTB, Costa JM, Ferreira JM. Fatigue behaviour of laser repairing welded joints. Eng Fail Anal 2007;14(8):1586-93.

[9] American Society for Testing and Materials. Standard test method for microhardness of materials. ASTM E 384. Annual Book of ASTM Standards, vol. 03.01; 2000.

[10] Flaman MT. Investigation of ultra-high speed drilling for residual stress measurements by the center hole method. Exp Mech 1982;22(1):26-30.

[11] Schajer G, Flaman MT, Roy G, Lu J. Hole-drilling and ring core methods. Handbook of measurement of residual stresses. Bethel: SEM; 1996. p. 5-34.

[12] Nobre JP, Batista AC, Coelho L, Dias, AM. Residual stresses evaluation by the incremental hole-drilling technique: a new computational tool. In: Proceedings of the fifth international conference on mechanics and materials in design, Porto; 2006. p. 24-6. 